\title{
AMIE (ARM MJO Investigation Experiment): Observations of the Madden-Julian Oscillation for Modeling Studies Science Plan
}

ARM Climate Research Facility Tropical Western Pacific Manus Site October 2011-March 2012

C Long

Principal Investigator

$\begin{array}{ll}\text { A DelGenio } & \text { P May } \\ \text { W Gustafson } & \text { S McFarlane } \\ \text { R Houze } & \text { P Minnis } \\ \text { C Jakob } & \text { C Schumacher } \\ \text { M Jensen } & \text { A Vogelmann } \\ \text { S Klein } & \text { YWWang } \\ \text { L Ruby Leung } & \text { X Wu } \\ \text { X Liu } & \text { S Xie } \\ \text { E Luke } & \end{array}$

March 2010

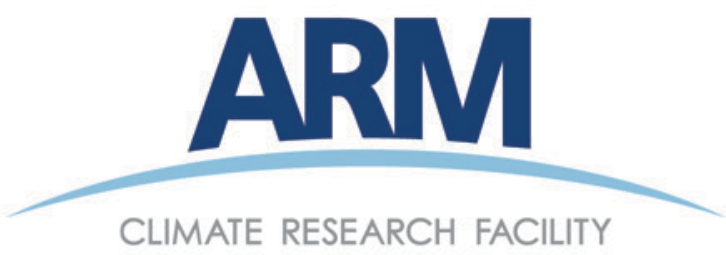




\section{DISCLAIMER}

This report was prepared as an account of work sponsored by the U.S Government Neither the United States nor any agency thereof, nor any of their employees, makes any warranty, express or implied, or assumes any legal liability or responsibility for the accuracy, completeness, or usefulness of any information, apparatus, product, or process disclosed, or represents that its use would not infringe privately owned rights Reference herein to any specific commercial product, process, or service by trade name, trademark, manufacturer, or otherwise, does not necessarily constitute or imply its endorsement, recommendation, or favoring by the U.S Government or any agency thereof The views and opinions of authors expressed herein do not necessarily state or reflect those of the U.S Government or any agency thereof. 


\section{AMIE (ARM MJO Investigation Experiment): Observations of the Madden-Julian Oscillation for Modeling Studies Science Plan}

C Long, Pacific Northwest National Laboratory

A Del Genio, NASA Goddard Institute for Space Studies

W Gustafson, Pacific Northwest National Laboratory

R Houze, University of Washington

C Jakob, Monash University, Australia

M Jensen, Brookhaven National Laboratory

S Klein, Lawrence Livermore National Laboratory

L Ruby Leung, Pacific Northwest National Laboratory

X Liu, Pacific Northwest National Laboratory

E Luke, Brookhaven National Laboratory

P May, Centre for Australian Weather and Climate Research (BoM/CSIRO)

S McFarlane, Pacific Northwest National Laboratory

P Minnis, NASA Langley Research Center

C Schumacher, Texas A\&M University

A Vogelmann, Brookhaven National Laboratory

Y WWang, Pacific Northwest National Laboratory

$\mathrm{X} \mathrm{Wu}$, Iowa State University

S Xie, Lawrence Livermore National Laboratory

March 2010

Principal Investigator Contact:

Dr. Charles N. Long

Pacific Northwest National Laboratory

P.O. Box 999, MSIN: K9-24

Richland, WA, USA 99352

Business Cell: 1 (509) 539-2807

Office: 1 (509) 372-4917

Fax: 1 (509) 372-6247

email: chuck.long@pnl.gov

Work supported by the U.S Department of Energy,

Office of Science, Office of Biological and Environmental Research 


\section{Abstract}

Deep convection in the tropics plays an important role in driving global circulations and the transport of energy from the tropics to the mid-latitudes. Understanding the mechanisms that control tropical convection is a key to improving climate modeling simulations of the global energy balance. One of the dominant sources of tropical convective variability is the Madden-Julian Oscillation (MJO), which has a period of approximately 30-60 days.

There is no agreed-upon explanation for the underlying physics that maintain the MJO. Many climate models do not show well-defined MJO signals, and those that do have problems accurately simulating the amplitude, propagation speed, and/or seasonality of the MJO signal. Therefore, the MJO is a very important modeling target for the ARM modeling community geared specifically toward improving climate models. The ARM MJO Investigation Experiment (AMIE) period coincides with a large international MJO initiation field campaign called CINDY2011 (Cooperative Indian Ocean experiment on intraseasonal variability in the Year 2011) that will take place in and around the Indian Ocean from October 2011 to January 2012. AMIE, in conjunction with CINDY2011 efforts, will provide an unprecedented data set that will allow investigation of the evolution of convection within the framework of the MJO. AMIE observations will also complement the long-term MJO statistics produced using ARM Manus data and will allow testing of several of the current hypotheses related to the MJO phenomenon.

Taking advantage of the expected deployment of a C-POL scanning precipitation radar and an ECOR surface flux tower at the ARM Manus site, we propose to increase the number of sonde launches to eight per day starting in about mid-October of the field experiment year, which is climatologically a period of generally suppressed conditions at Manus and just prior to the climatologically strongest MJO period. The field experiment will last until the end of the MJO season (typically March), affording the documentation of conditions before, during, and after the peak MJO season. The increased frequency of sonde launches throughout the experimental period will provide better diurnal understanding of the thermodynamic profiles, and thus a better representation within the variational analysis data set. Finally, a small surface radiation and ceilometer system will be deployed at the PNG Lombrum Naval Base about $6 \mathrm{~km}$ away from the ARM Manus site in order to provide some documentation of scale variability with respect to the representativeness of the ARM measurements. 


\section{Contents}

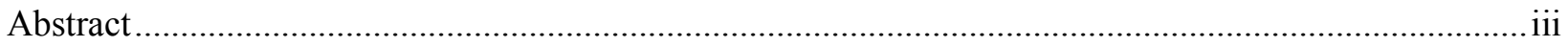

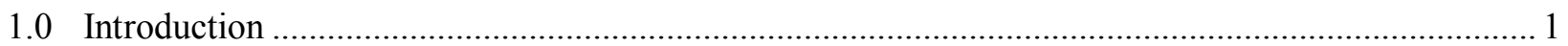

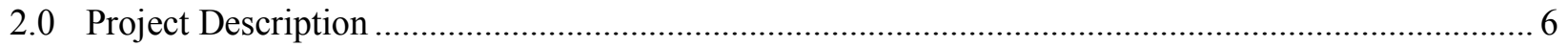

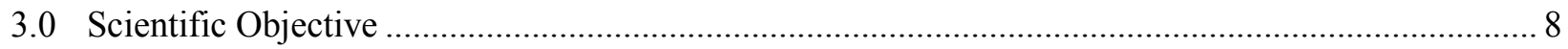

3.1 Science/modeling questions to be addressed by AMIE ..................................................... 8

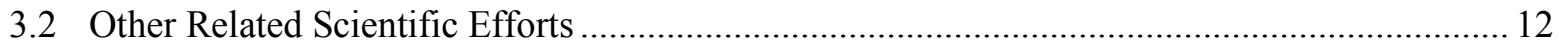

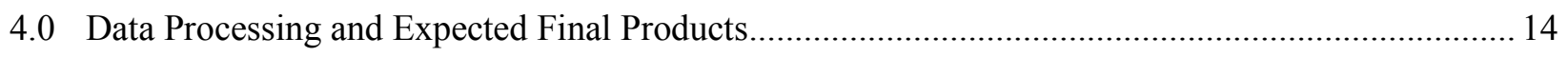

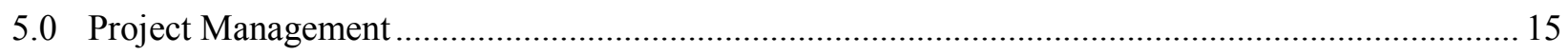

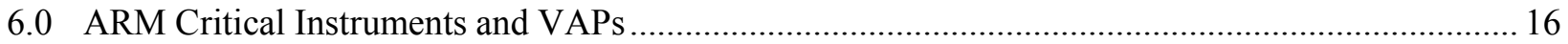

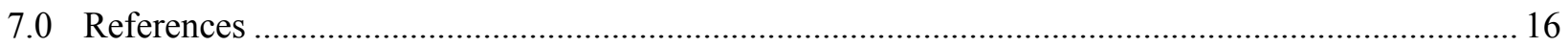

\section{Figures}

1 The Manus downwelling SW and retrieved fractional sky cover ................................................. 2

2 Cluster analysis by cloud regime using ISCCP satellite data from Chen and Del Genio 2009, Climate Dynamics. 4

3 Manus MJO composites of ARSCL cloud profiles, precipitation, and RH anomaly profiles............. 5

4 Conceptual design of CINDY2011 in the Indian Ocean and relationship to AMIE located on Manus Island on the eastern edge of the Maritime Continent ...................................................... 6

5 BRFAS radiometer system deployed at the COPS Hornisgrinde site in 2007 ................................. 7

6 Space-time spectrum of the symmetric component of $15^{\circ} \mathrm{N}-15^{\circ} \mathrm{S}$ precipitation in the GOES GPI data set and in the GFDL, NCAR, and GISS IPCC AR4 GCMs ........................................ 9

7 Climatological TRMM mean November-April rainfall and 30-90 day rainfall variance in the tropical West Pacific region. 


\subsection{Introduction}

Deep convection in the tropics plays an important role in driving global circulations and the transport of energy from the tropics to the mid-latitudes. Understanding the mechanisms that control tropical convection is a key to improving climate modeling simulations of the global energy balance. One of the dominant sources of convective variability in the tropical western Pacific (TWP) is the Madden-Julian Oscillation (MJO), which has a period of approximately 30-60 days (Madden and Julian 1994; Zhang 2005). The MJO is an eastward-propagating, slow, moist Kelvin-Rossby wave with signatures, among others, in the wind field and convective activity. In the west Pacific, an MJO cycle includes a convectively active phase with widespread maritime convection and very high cloud fractions and a suppressed phase with reduced convective activity. The strength of the MJO varies relative to other sources of variability but tends to be strongest during the boreal winter.

The importance of the MJO in global weather and climate, as well as the urgency for expediting its study to improve intraseasonal-seasonal prediction, are well recognized by the research community. The THORPEX International Science Plan ${ }^{1}$ lists the MJO as one of the targets in its research objectives. Two international workshops, organized by ECMWF $^{2}$ and WCRP/THORPEX ${ }^{3}$ in 2003 and 2006 respectively, have focused on the MJO and tropical intraseasonal variability. The WCRP/THORPEX workshop specifically recommended a field experiment to target MJO initiation. Substantial improvement of extended-range/subseasonal forecasts of the MJO is one of the overarching goals of the WCRPWWRP/THORPEX international initiative Year of Tropical Convection (YOTC) ${ }^{4}$. US CLIVAR has established an MJO Working Group ${ }^{5}$ with tasks on several issues related to simulation and prediction of the MJO. The important role of the MJO in modulating tropical cyclones is emphasized in a recent report of the U.S. Climate Change Science Program ${ }^{6}$.

There is no agreed-upon explanation for the underlying physics that maintain the MJO. Many climate models do not show well-defined MJO signals, and those that do have problems accurately simulating the amplitude, propagation speed, and/or seasonality of the MJO signal (Inness and Slingo 2003; Lin et al. 2004; Lin et al. 2006; Zhang et al. 2006). Modeling studies have shown that simulation of the MJO is very sensitive to the formulation of the deep convective scheme and to aspects of the model microphysics, including the vertical profile of diabatic heating (Lin et al. 2006). Therefore a field campaign examining the MJO is a very important and useful modeling target for the ASR modeling community geared specifically toward improving the representation of deep convection and cloud microphysics in the models. The ARM MJO Investigation Experiment (AMIE) will provide an extensive surface-based data set to better understand the physical mechanisms behind the MJO, allowing investigation of the details of convection within the framework of the MJO and embedded in the long-term MJO statistics that have been produced using ARM Manus data. Additionally, the synergy with the CINDY2011 campaign in the Indian Ocean will allow study of the propagation and evolution of the MJO and its interaction with the Maritime Continent, which is particularly problematic for forecast and climate models.

\footnotetext{
${ }^{1} \mathrm{http}: / /$ www.wmo.ch/pages/prog/arep/thorpex/documents/brochure_e.pdf

${ }^{2} \mathrm{http} / / /$ www.ecmwf.int/newsevents/meetings/workshops/Intra-seasonal_variability/index.html

${ }^{3} \mathrm{http}: / /$ cdsagenda5.ictp.trieste.it/pdf_display.php?ida=a04205

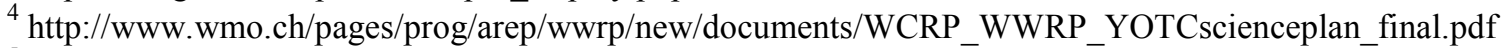

${ }^{5} \mathrm{http} / / /$ www.usclivar.org/Organization/MJO_WG.html

${ }^{6} \mathrm{http}: / /$ www.climatescience.gov/Library/sap/sap3-3/final-report/
} 
The ARM Manus site was intentionally chosen to be in a complex convectively active region influenced by the Maritime Continent and tropical oscillations on a range of time scales, including the MJO. Our recent analyses (Figure 1) confirm that the ARM Manus measurements exhibit a strong MJO signal, despite concerns that the ARM Manus measurements are surface-point measurements. The time series of clear-sky and all-sky downwelling shortwave irradiance is shown in Figure 1A, and the corresponding downwelling SW cloud radiative forcing (the difference between the measured and clear-sky SW divided by the clear-sky SW) and the daylight fractional sky cover are shown in Figure 1B. The temporal detection of the MJO signal is illustrated in Figure 1C as a wavelet power spectrum analysis of the cloud radiative forcing $(\mathrm{CRF})$, while 1D shows the Fourier power spectrum with a significant peak in the 5060 day range.
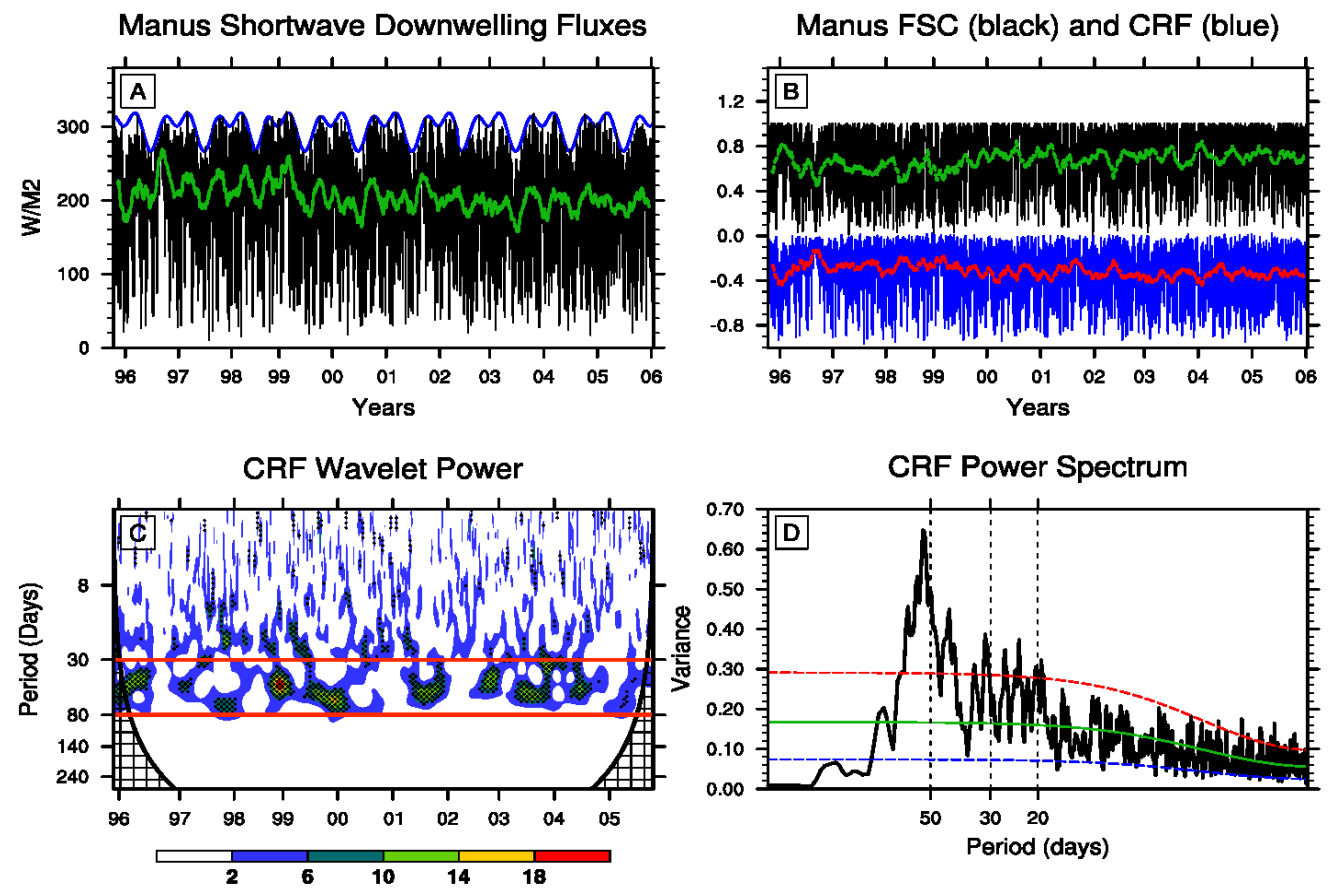

Figure 1. The Manus downwelling SW and retrieved fractional sky cover (FSC). (A) The time series including the clear-sky (CSWDN, blue) and all-sky (SWDN, black) downwelling SW. The green line indicates a 60-day running mean. (B) Time series of cloud radiative forcing (CRF, blue) and fractional sky cover (FSC, black) and 60-day running mean (red and green, respectively). (C) Wavelet power of CRF (contour). Cross-hatched regions on either end indicate the "cone of influence," in which the edge effect becomes important. Statistical significance of wavelet power is stippled. (D) Fourier power spectrum of the CRF (black line) overlaid by best-fit red noise spectrum (green) and a 95\% confidence envelope (dashed lines, red and blue). The first three harmonics of the annual cycle are removed before computing the spectrum.

The Manus site provides continuous measurements of cloud profiles via the vertically pointing MMCR and MPL, but in order to carry out a modeling study of the MJO, it would be very useful to make additional measurements for an MJO cycle or cycles. A key instrument for modeling studies is a scanning precipitation radar, which links the larger-scale convection to the cloud profiles observed by the MPL and MMCR and provides precipitation amounts for budget calculations. The scanning precipitation radar measurements would need to provide coverage of much of the island and the surrounding ocean. 
An X-band radar was deployed at Manus during TOGA-COARE (Ushiyama et al. 1995), and measurements from this radar showed significant spatial variability in rainfall and a marked land/ocean contrast in the diurnal cycle. Additionally, the Australian Bureau of Meteorology (BoM) C-band, polarimetric radar (C-Pol) located at Gunn Point was a significant contribution to the Tropical Warm Pool-International Cloud Experiment (TWP-ICE), and the C-Pol data, among other uses, have proved invaluable as a constraint for production of the ARM Variational Analysis Model Forcing data product (Xie et al. 2009, Zhang and Lin 1997, Zhang et al. 2001) for TWP-ICE. The TWP-ICE efforts and other earlier studies (i.e., Xie et al. 2004) have shown that the large constraint of knowing the area precipitation makes it possible to produce a reasonable large-scale forcing data set for modeling studies over the Manus area using the variational analysis approach with the ECMWF reanalysis data that ARM collects as an external data product for the TWP sites. Though scientifically desirable, it is impractical to surround the ARM Manus site with a number of ancillary sonde launch sites due to the general lack of infrastructure, living space, medical facilities, and land surface at appropriate distances as was the case for TWP-ICE. However, increased sonde launches at the Manus site plus area precipitation from a C-band, polarimetric radar will be sufficient, as the TWP-ICE experience has shown.

Linking the standard ARM Manus measurements with a scanning precipitation radar, as well as other spatially representative data sources such as the proposed scanning cloud radar, satellite retrievals, and ECMWF analyses, affords a unique opportunity to better understand the physical mechanisms behind the MJO phenomenon on many scales. An example of the synergy between satellite retrievals and the ARM Manus surface measurements is shown in Figures 2 and 3, taken from Chen and Del Genio (2009). ISCCP cloud regime classification for the Manus longitude (Figure 2, left) is used to produce a climatological analysis by MJO phase (Figure 2, bottom right). These results are then related to ARM Manus measurements of vertical cloud distribution and RH anomaly, as well as precipitation (Figure 3). To relate analyses such as those presented in Figures 1 through 3, a data set that can be used for a detailed look at the thermodynamic profile and spatial context differences will allow, among other things, the analysis of detailed modeling studies to determine if they exhibit the same characteristics as a function of MJO phase. A better understanding of these mechanisms will certainly lead to improvement in the ability of climate models to better represent the occurrence, phase, timing, and strength of the MJO, especially in conjunction with the CINDY2011 activities.

CINDY2011 will take place in and around the Indian Ocean from October 2011 to January 2012 (Figure 4). CINDY2011 is designed to improve our knowledge of the intraseasonal variability in the tropical Indian Ocean with a focus on the initiation process of convection in the MJO. CINDY2011 can be regarded as a follow-up project of MISMO (Mirai Indian Ocean cruise for the Study of the MJOconvection Onset), which took place in the central Indian Ocean from late October to early December 2006. While MISMO captured the onset of a weak MJO, analyses revealed that the recharge-discharge process might play a key role in the development of the intraseasonal convection. MISMO studies also suggest that equatorial Kelvin and Rossby waves might play a crucial role in the initiation process. However, it is difficult to deduce the relationship with such large-scale phenomena from MISMO's limited areal coverage and one month of data. Hence a new field experiment, CINDY2011, is planned to collect in situ atmospheric and oceanic data over an intraseasonal period with a large-scale observation network as a multi-national effort. In addition to the observational component of the experiment, numerical research is also an important component of this experiment to enhance the skill of MJO simulation. The ultimate goal is not only to promote knowledge of the initiation process of MJOconvection, but also to improve weather and climate prediction. 

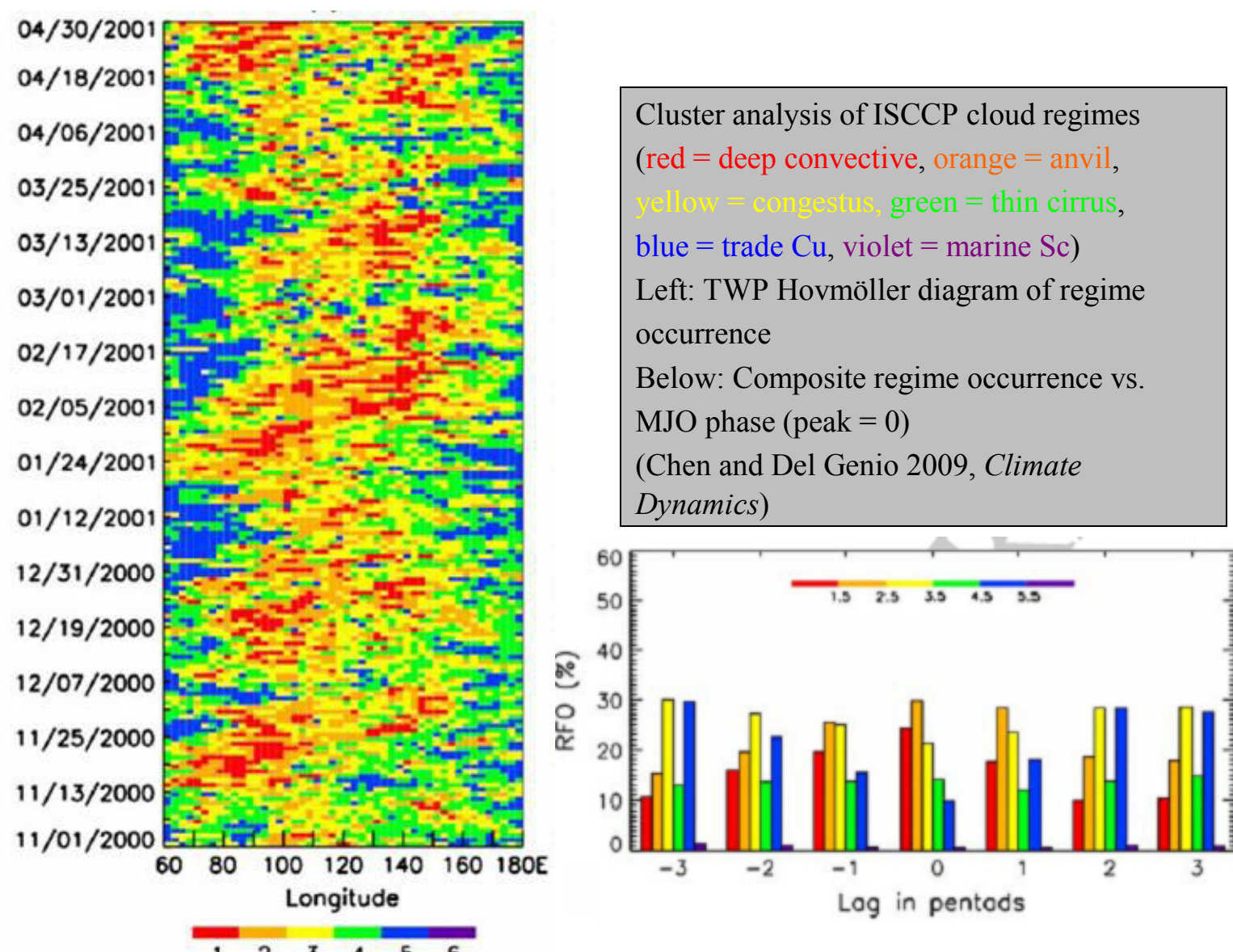

Figure 2. Cluster analysis by cloud regime using ISCCP satellite data from Chen and Del Genio 2009, Climate Dynamics. Vertical black line represents Manus longitude. 


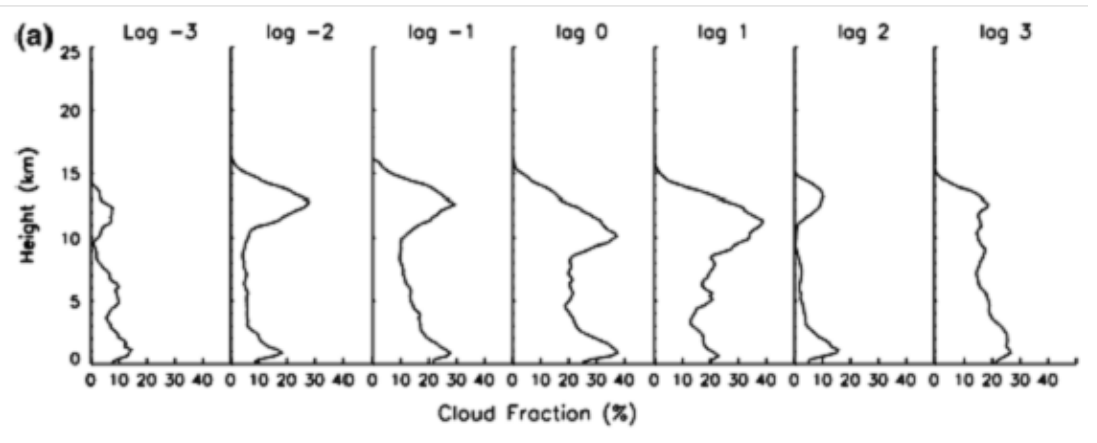

(b)
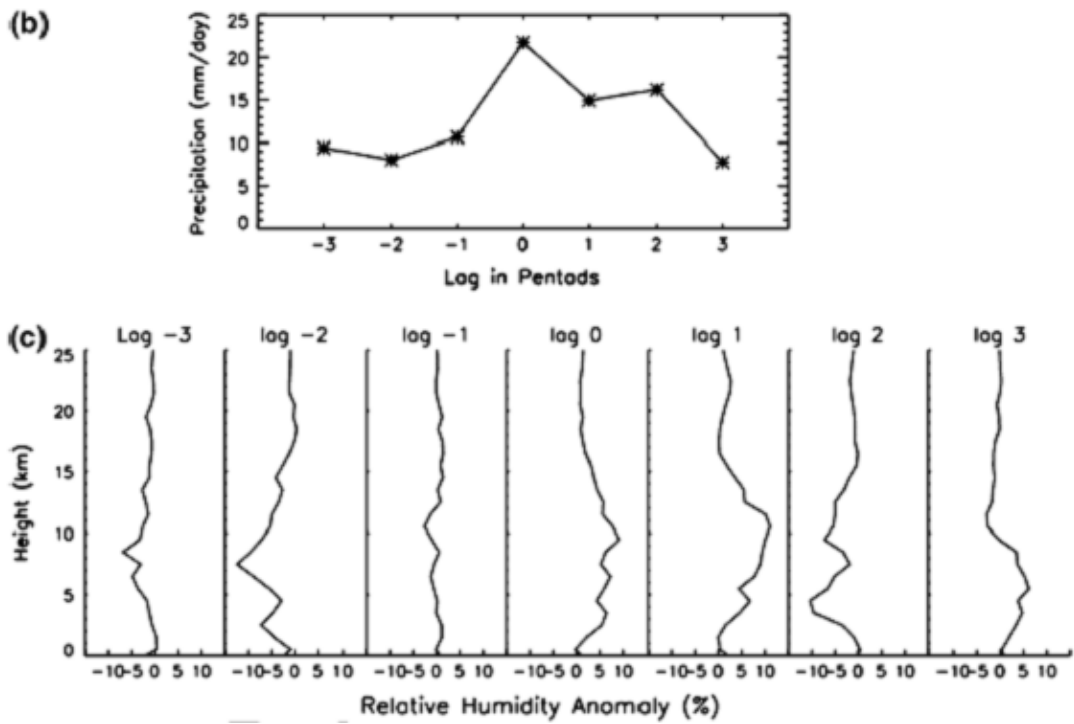

Figure 3. Manus MJO composites of ARSCL cloud profiles, precipitation, and RH anomaly profiles (from Chen and Del Genio 2009, Climate Dynamics).

While the mechanisms underlying the MJO are uncertain, we are confident that the oscillation is related to coupling between the large-scale atmospheric and sea state with convective processes. The combination of measurements of three-dimensional cloud and precipitation structure, radiative and latent heating profiles from the various remote sensors, frequent soundings, flux measurements, and large-scale environmental analyses over an extended period long enough to encompass a significant MJO season life cycle will provide invaluable data to help unravel the key physics and feedbacks associated with the MJO coupled wave and constrain proposed MJO mechanisms as outlined below.

Combining CINDY2011 and AMIE (Figure 4, top) affords the opportunity to include study of MJO propagation and evolution. To significantly increase the synergy, we will also be submitting a proposal to deploy the AMF2 and (with NSF/JAMSTEC funding) a C-band radar on the island of Gan in the Indian Ocean (see Figure 4, bottom) as part of the CINDY2011 network. A coordinated MJO experiment like AMIE/CINDY2011 is an opportunity that will likely not reoccur for at least a decade or more. 


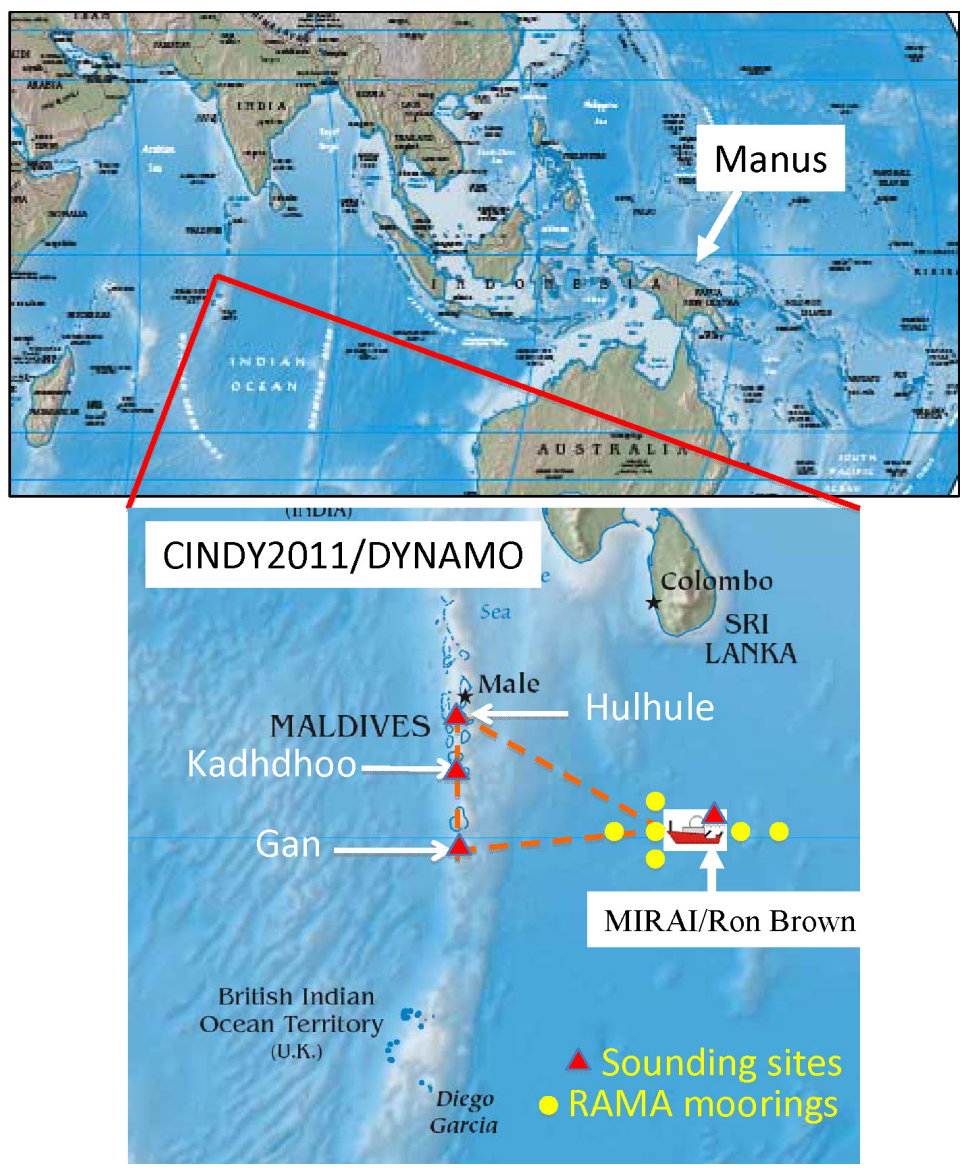

Figure 4. Conceptual design of CINDY2011 in the Indian Ocean (bottom) and relationship to AMIE located on Manus Island on the eastern edge of the Maritime Continent (top). While CINDY2011 is aimed at the study of MJO initiation, synergy with AMIE allows study of MJO west-to-east propagation and evolution.

\subsection{Project Description}

In general, the principal instrumental components of the proposed field campaign include a C-band, polarimetric precipitation radar (denoted as C-POL to differentiate it from the Australian Bureau of Meteorology's C-Pol radar in Darwin), deploying a small set of radiometers and a ceilometer to document local scale spatial variability, deploying a tower to measure turbulent surface heat fluxes, and increasing the frequency of sonde launches. It is our understanding that some of the funds from the American Recovery and Reinvestment Act (ARRA) grant to ARM will be used to deploy a C-POL radar, as well as a scanning dual-wavelength cloud radar and a surface flux (eddy correlation) system, at the Manus site. The combination of scanning C-POL and cloud radars affords the opportunity to test some of the current hypotheses regarding the importance of moisture convergence and shallow convection in preconditioning the atmospheric column as a precursor to the initiation and propagation of the MJO peak convection. The surface flux system affords the testing of some of the hypotheses regarding propagation through the Maritime Continent area, where MJO strength diminishes and models have the most difficulty capturing the characteristics of the MJO. It is hypothesized that the representation of land/air exchanges in the Maritime Continent plays a significant role. 
The small radiometer system will be one of the Basic Radiative Flux Analysis Systems (BRFAS) that were deployed at the Hornisgrinde and Rhine Valley sites during the COPS campaign (Figure 5). These small footprint systems include measurements of downwelling SW and LW; the SW total, direct, and diffuse components; and an air temperature and relative humidity probe logged by a Campbell CR23X data logger. The system is remotely operated and monitored, and data are collected via the internet. Internet access will be through wireless connection to the ARM site (for details, see ARM Resources Required section). Additionally, we desire the deployment of a collocated ceilometer at the ancillary site to assess the local-scale variability of non-precipitating cloud. The ceilometer could be one of the ARM spares, or alternately the PARSL ceilometer could be used.

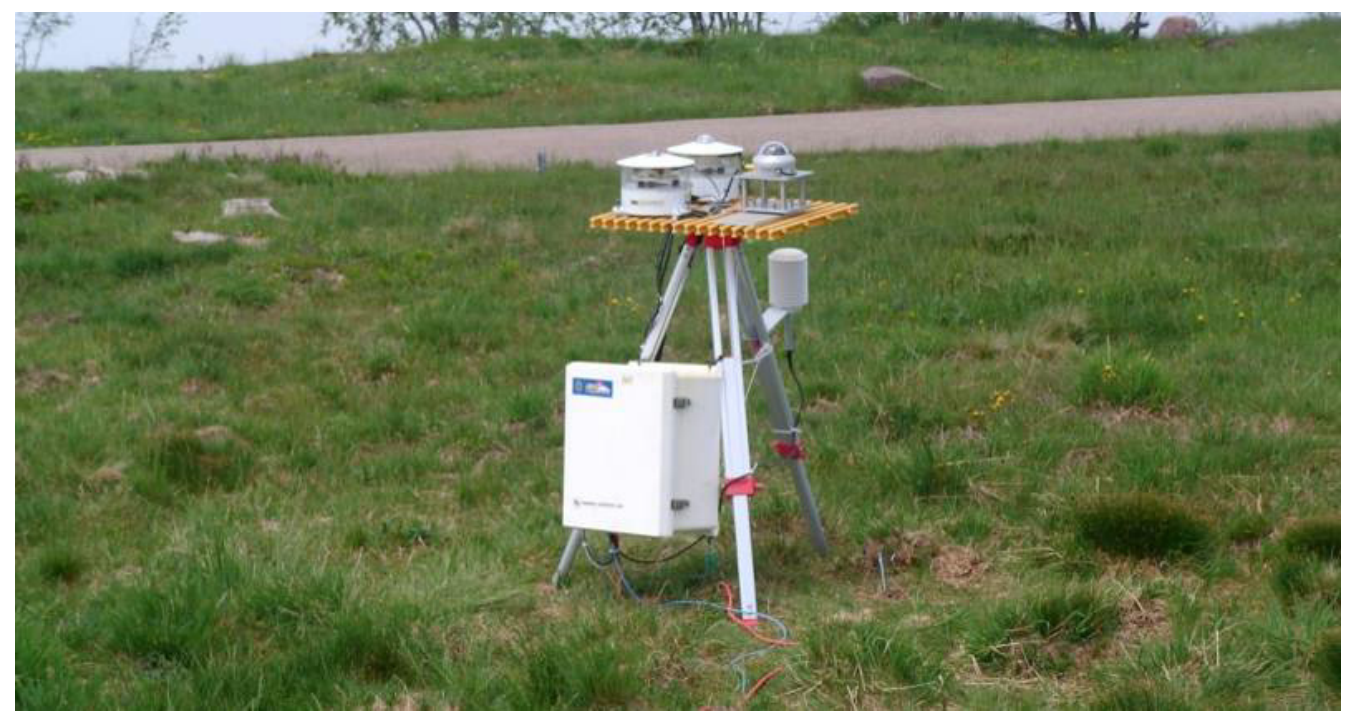

Figure 5. BRFAS radiometer system deployed at the COPS Hornisgrinde site in 2007.

The final principal component of the field campaign concerns an increase in sonde launches at the ARM Manus site. In order to achieve a better understanding of the diurnal aspects of the thermodynamic profiles, we propose sondes be launched every three hours (eight sondes per day) affording the documentation of conditions before, during, and after the peak MJO season. While climatologically this intensive sonde launch period should start about mid-October and last through mid-March, the actual MJO season in a given year can vary to some extent. Thus we propose to take advantage of the CINDY2011/AMIE synergy, as well as Australian BoM MJO forecasts, to determining the exact start and end dates for the intensive sonde launches to be sure to fully capture conditions before, during, and after the peak MJO season while at the same time minimizing costs for the field campaign.

Knowing when to begin the intensive launch period requires prediction of the local MJO event. A number of studies have shown significant skill for MJO prediction out to 10-15 days (e.g., Waliser et al. 1999, Wheeler and Weikmann 2001). These approaches have been refined, and an approach based on EOF analyses that does not depend on band pass filtering, and hence has no lags, has been developed by Wheeler and Hendon (2004). Wheeler and Hendon found two principal EOFs using area averages of OLR, 850, and $200 \mathrm{hPa}$ winds - the so-called RMM1 and RMM2. For a well-defined MJO event, the amplitude and phase of a phase diagram with RMM1 on one axis and RMM2 on the other is both an excellent diagnostic as well as a predictive objective tool for MJO events. These forecasts are available in real time and are heavily used in the tropical forecasting community. These phase diagrams trace the active/inactive areas across the Indian and Pacific basins. We have access to the full range of satellite and 
real-time NWP products, as well as diagnostics such as the MJO prediction, provided by the Australian Bureau of Meteorology which we will take advantage of during the field campaign.

Given a typical ascent rate, a three-hourly sonde launch schedule likely would give enough time for the balloon to ascend, burst, and fall before the next sonde is launched. However, it is possible that it might be necessary to switch between sonde channels during the intensive three-hourly sonde launch phase of the experiment.

\subsection{Scientific Objective}

The overarching scientific objective of the campaign is the collection of a data set useful for improving understanding and modeling efforts with respect to the MJO in the tropical western Pacific area. The data collected will include that from the ARM Manus site itself (including a scanning C-band radar), increased sonde launches, plus radiation and ceilometer data from an ancillary site located at the PNG Lombrum Naval Base. Additionally, various satellite data, and products such as that of the ECMWF analyses, will be used to give a larger area perspective and as input for production of a variational analysis data set for the experimental period.

\subsection{Science/modeling questions to be addressed by AMIE}

The MJO is a leading mode of cloud and rainfall variability in the TWP and an important metric of the realism of a model's cloud-convection-radiation interactions. Unfortunately, the IPCC AR4 GCMs simulate the MJO rather poorly (Figure 6). The magnitude of simulated intraseasonal precipitation variance is greatly underestimated, propagation speeds tend to be too fast, and the ratio of eastward-towestward propagating variance is too small. This calls into question the models' ability to simulate cloud effects on longer-term climate change time scales.

Many theories have been proposed to explain the MJO (e.g., Benedict and Randall 2007), each with some support in observations, but with no consensus having formed in favor of any particular mechanism. AMIE will provide observational constraints on several of these hypotheses. One recent proposal (Sobel et al. 2008) is that surface energy fluxes drive the MJO. This proposal is based on the observation that although mean precipitation is comparable over the tropical West Pacific Ocean and the islands of the Maritime Continent, the variance of precipitation in the 30-90 day period band is much weaker over the islands (Figure 7). An additional result that supports this idea is that several GCMs produce incipient MJOs in the Indian Ocean, only to have them weaken and terminate as they propagate eastward and cross the Maritime Continent. Perhaps the most important difference between land and ocean is the large net upward surface energy flux (primarily latent heat flux) over ocean, whereas over land, low thermal inertia guarantees little heat storage on MJO time scales and thus a near-zero net heat flux. The Sobel et al. hypothesis is that the absence of this heat flux weakens the MJO over land. The surface flux includes radiative (SW and LW) and turbulent (LH and $\mathrm{SH}$ ) flux components, which vary with humidity, cloud cover, soil moisture, surface wind, and surface temperature. Thus, the land surface can exhibit small overarching net heat flux in many ways, and different combinations of fluxes that produce small net flux may have very different effects on convection during the MJO. ARM already measures the surface radiative fluxes on Manus, though the current upwelling SW and LW measurements made only at about $1 \mathrm{~m}$ height over the site's mown grass surface is not nearly representative of Maritime Continent land 
areas. We propose to add a surface heat flux tower to measure the turbulent heat fluxes as well, plus relocate the upwelling radiation measurements to the tower to better represent Maritime Continental land surfaces. These data would be contrasted with those of the nearest moored buoys (TAO array) over ocean several hundred kilometers away. We also propose to conduct three-hourly soundings at Manus for the duration of AMIE. This will allow us to document the diurnal cycle in temperature and humidity profiles, and especially the diurnal growth and decay of the boundary layer, that accompany diurnal variations in surface heat flux components. The presence or absence of diurnally driven convection during the suppressed vs. disturbed phases of the MJO, and whether this disrupts the MJO, will be understood via precise knowledge of the thermodynamic structure close to the time at which convection occurs.

\section{(a) GPI}

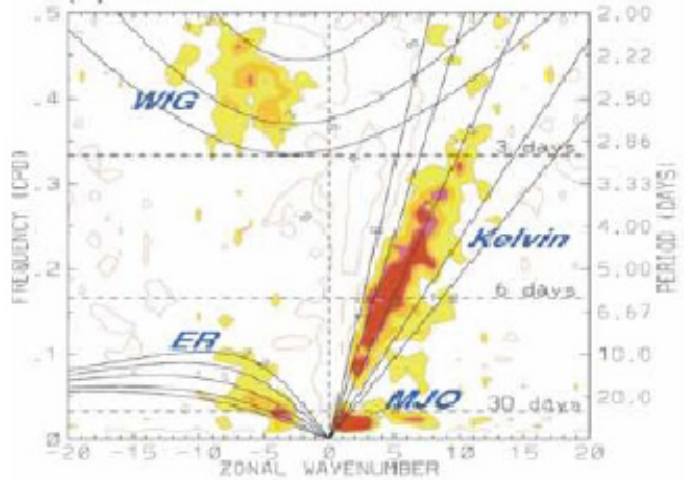

(e) $\operatorname{CCSM} 3$

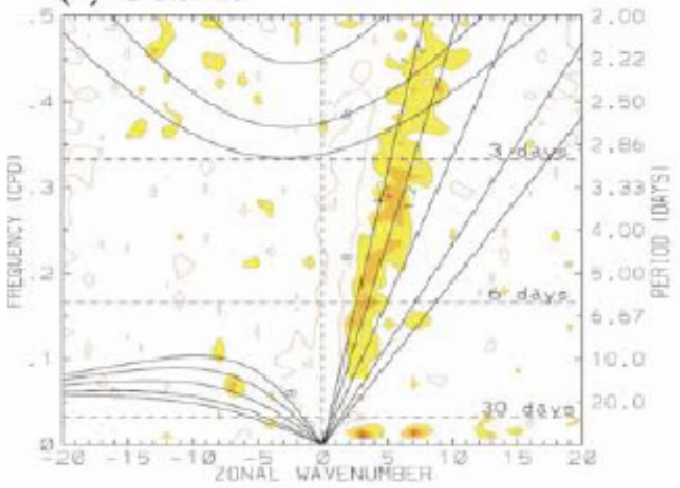

(d) GFDL2.1

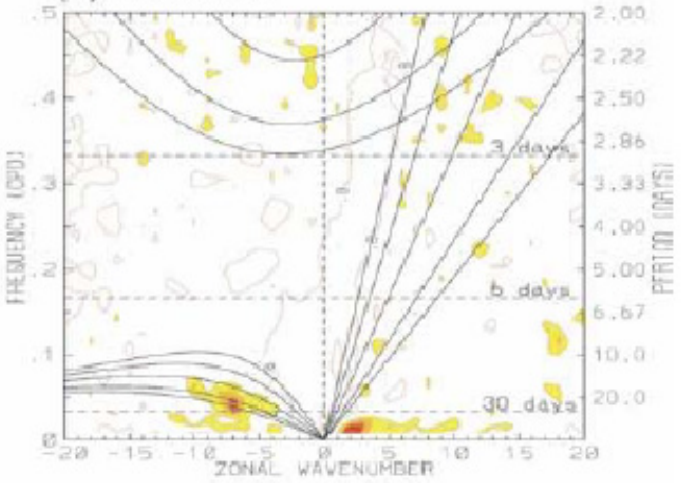

(h) GISS-ER

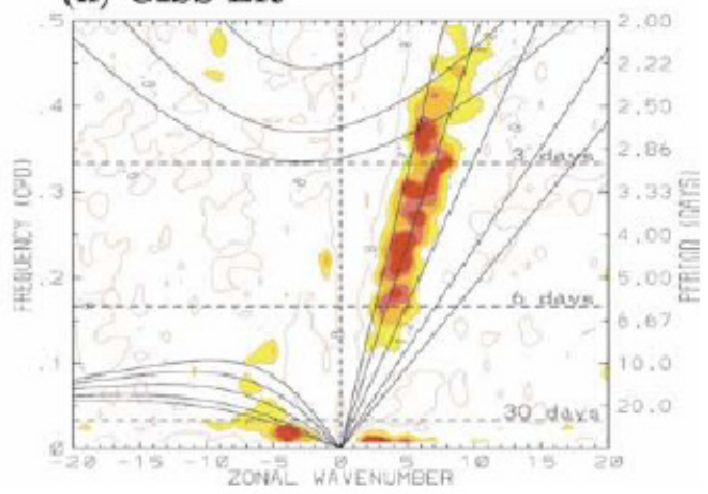

Figure 6. Space-time spectrum of the symmetric component of $15^{\circ} \mathrm{N}-15^{\circ} \mathrm{S}$ precipitation in the GOES GPI data set (upper left) and in the GFDL (upper right), NCAR (lower left), and GISS (lower right) IPCC AR4 GCMs (Lin et al. 2006). 


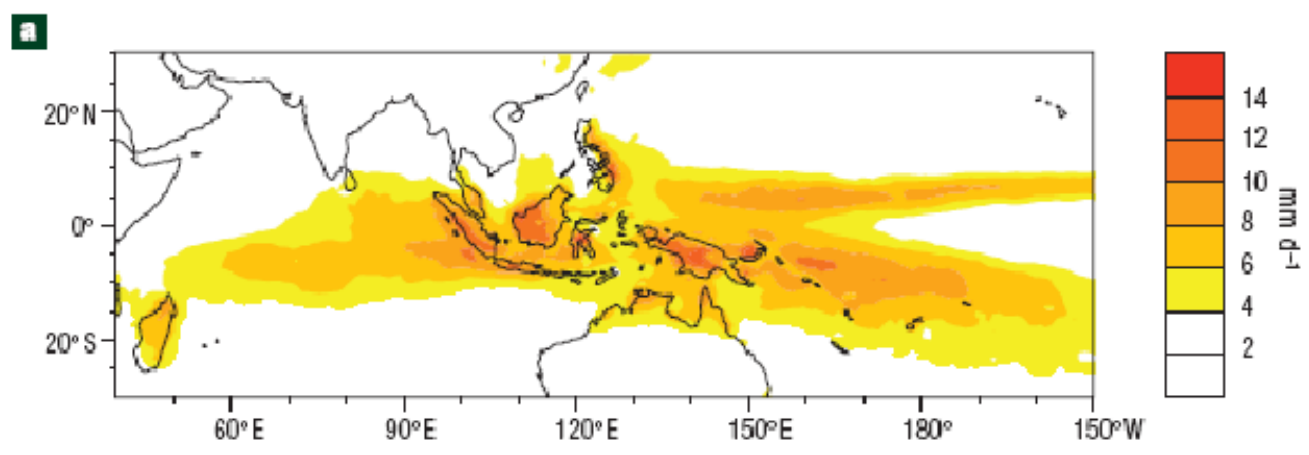

a

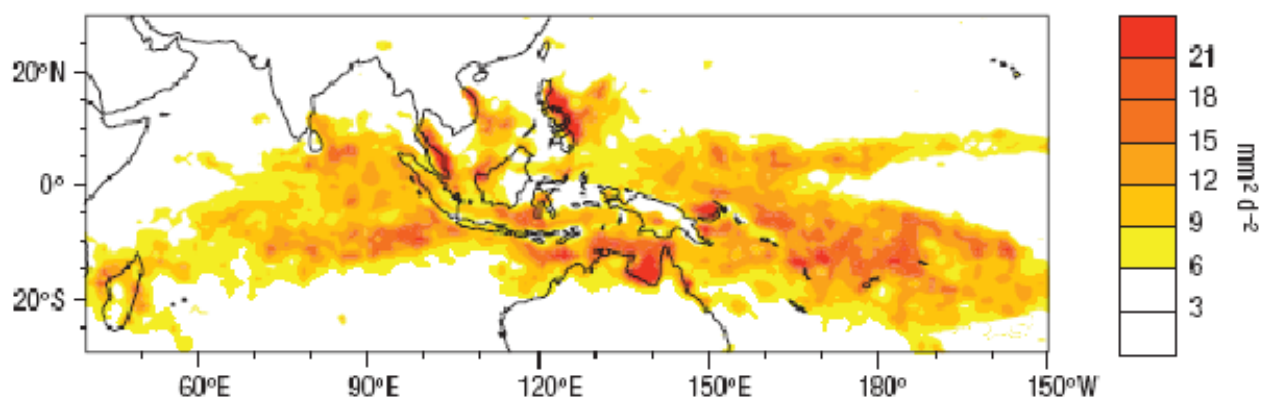

Figure 7. Climatological TRMM mean November-April rainfall (top) and 30-90 day rainfall variance (bottom) in the tropical West Pacific region (Sobel et al. 2008).

We also strongly support the planned installment of a C-POL radar at Manus, which is critical to the success of AMIE. This would accomplish multiple objectives. First, with a $150-\mathrm{km}$ range for a full volume scan, a C-POL radar would document the vertical structure of convection and rainfall over the adjacent ocean as the MJO disturbed phase approaches Manus and any change in its character once the disturbance reaches land. These measurements would explain how a change in surface fluxes results in a change in convection. Conducting AMIE during the same time frame as CINDY2011 will further expand the context of AMIE observations by documenting the initiation of MJO events in the Indian Ocean before they propagate east past Manus. This will be important for the question of how the MJO changes as it passes over the Maritime Continent and how this differs in observations vs. models. Second, largescale precipitation information from a C-POL radar plus three-hourly soundings at Manus would permit the construction of an advective forcing data set to drive single-column models (SCMs) and cloudresolving models (CRMs). A large-scale array of sounding sites, as existed during TWP-ICE, will not be available at Manus. However, Hume et al. (2007) have shown that an ensemble of NWP model forcing data sets can provide an acceptable means of driving SCMs and CRMs, and Jakob et al. (2008) have shown that the most important contributor to variability in ensemble forcing is the large-scale rainfall input to the constrained variational analysis used to construct the forcing. Thus, with a C-POL radar at Manus and existing NWP model analyses, it should be possible to derive a forcing product for the duration of the field campaign that can be used to test whether SCMs and CRMs are capable of reproducing the progression of the MJO.

An advective forcing data set for Manus also produces an estimate of large-scale heating (Q1) and drying (Q2) rates as a function of MJO phase. Mapes (2000) has proposed a stratiform instability mechanism for the MJO that invokes the difference between the vertical profile of heating in the convective cell region 
vs. the stratiform anvil region of convective clusters. In this hypothesis, heating and drying by convection, which have a single broad lower/midlevel peak, stabilize the atmosphere and damp longerterm variability. However, the trailing stratiform anvil region, which has a dipole Q1 and Q2 structure, cools and moistens the lower troposphere via rain evaporation. This can overcome convective inhibition and the reduction of boundary layer moist static energy by downdraft outflow and destabilize the column to further convection. In Mapes' simple model, this generates a larger-scale propagating instability that resembles the MJO. The advective forcing data set will document whether this progression of heating/drying structure and column destabilization occur in the MJO. The C-POL radar will determine whether such changes in heating and drying profiles are correlated with the transition from convective to stratiform rain. The three-hourly soundings and surface flux tower may detect the effects of downdraft outflows on boundary layer moist static energy and latent heat flux. Finally, SCMs and CRMs driven by the forcing can be evaluated to see whether their cumulus parameterizations (or explicitly resolved convection) produce a similar progression of heating and drying profiles, and whether their downdrafts under- or over-stabilize the boundary layer.

CRM-simulated cloud-scale properties have shown great value in improving the representation of cloudrelated processes in GCMs, such as the parameterization of convective momentum transports and the inclusion of subgrid cloud distribution in the radiation calculation. Wu et al. (2007) showed that a CRMbased deep convection trigger plays a significant role for improving the global distribution of precipitation frequency and MJO and ENSO simulations. The AMIE and CINDY2011 field campaigns will provide unique forcing data sets for the CRM simulations over the western Pacific and Indian Ocean. Long-term CRM simulations will then be performed using the ECMWF reanalysis, constrained by precipitation, surface heat fluxes and radiation fluxes and TOA radiative fluxes, and used to evaluate GCM climate simulations and efforts to improve the convection, cloud, and radiation parameterizations.

Perhaps the most popular current idea about the MJO is that it results from a "recharge-discharge" mechanism involving the transition between shallow and deep convection as tropospheric humidity varies (Bladé and Hartmann 1993, Hu and Randall 1994, Kemball-Cook and Weare 2001). In this hypothesis, during the suppressed phase of the MJO a dry free troposphere is a hostile environment for rising convective parcels. The parcels entrain dry air and lose their buoyancy at low altitudes, but when they do they detrain moisture, making the environment somewhat less hostile for the next convective event, which thus penetrates a bit deeper before detraining. Eventually, the troposphere becomes moist enough for deep convection to occur, completing the transition to the disturbed phase of the MJO. It is already known from the ARSCL data set at Manus that such transitions from shallow to deep cloudiness occur over the island as a function of MJO phase (see Figure 3, top plot), and that these are accompanied by tropospheric humidity variations consistent with the recharge-discharge idea. What is not known is whether similar variations occur over the open ocean, where the MJO is initiated and is strongest. There is some evidence from ISCCP that this is the case (Chen and Del Genio 2009), but ISCCP, being a passive remote sensing product, has ambiguities and known errors in cloud top height in complex cloud situations. If ARM installs a dual-channel scanning cloud radar at Manus as part of the ARRA funds, we will be able to determine 3D cloud structure over the nearby ocean as accurately as ARSCL does above Manus. Documentation of a recharge-discharge style transition of convective cloud depths would provide a stringent test for SCM cumulus parameterizations, which are known to be insensitive to free tropospheric humidity because of inadequacies in their entrainment parameterizations (Derbyshire et al. 2004). We note also that the scanning C-POL data will be essential for providing much of this information and would afford the opportunity to look at the PDFs of the cell characteristics or other 
indices of convective depth as a function of MJO phase or other regime definitions. The algorithms needed for these analyses are already developed, and these products can be provided as part of the AMIE data.

Thus, the AMIE campaign is intended to address several important scientific questions, including:

- What are the primary cloud, precipitation, and thermodynamic property differences between the active and suppressed phases of the MJO, including variations linked to interactions with the diurnal cycle, topography, and surface flux variability?

- Can enhanced characterization of clouds, precipitation, and thermodynamic fields during the active and suppressed phases of an MJO cycle provide new understanding and insight for improving convection and cloud parameterizations and MJO simulations in GCMs?

- How well do the ARM Manus site measurements capture the local scale variability and characteristics of the larger Manus area?

To address this last question, we will conduct comparative statistical analyses similar to those employed in the analysis of Nauru99 and the Nauru Island Effects Study, which compared similar ancillary site data to the ARM Nauru site data (McFarlane et al. 2005). These analyses will not only include overall aggregate comparisons, but comparisons segregated by factors such as wind direction, cloud regime, and MJO phase, as well as a component of temporal scales. Thus we will be able to document to what extent and on what time scales the ARM site data actually represents larger scales as opposed to local scale influences. These analyses will also benefit greatly should the proposed scanning cloud radar be deployed and operating at the ARM Manus facility during AMIE.

Increased sonde frequency and the C-band scanning radar, along with the ARM standard measurements, will be used as the primary means of addressing the first two questions above. The ancillary site data will be instrumental in answering the third question, but also will contribute to the first question as well. The satellite and ECMWF analysis products will contribute to answering all three of the above questions.

\subsection{Other Related Scientific Efforts}

As is often the case, all or part of the data collected during the proposed field campaign lend themselves to other studies as well. Some of these related studies have been proposed by a number of the field campaign Science Team members and include:

$\underline{\text { Radiative heating rates in deep convective clouds - Active vs. Suppressed phases }}$

A study by Lin et al. (2004) suggested that the inability of many climate models to simulate realistic representations of the MJO may be caused by systematic diabatic heating profile errors in the models. We are currently using the MJO time series analyses (Wang et al. 2010) and a time series of radiative heating profiles derived from MMCR data at Manus (Mather et al. 2007) to determine how the vertical structure of the radiative heating changes with MJO phase. However, the MMCR vertical profiles are of limited use in deep convective clouds because of the attenuation of the MMCR reflectivity during heavy precipitation. The combination of the C-Pol and MMCR data will provide a useful data set to better define the radiative heating profile in deep convective clouds and how it relates to the latent heating profile. Deep convective cloud systems are the most obvious feature in satellite images of tropical 
latitudes due to their relatively high albedo and low infrared brightness temperature. Estimates of the topof-atmosphere (TOA) cloud radiative forcing of deep convective clouds using observations from the Earth's Radiation Budget Experiment (ERBE) show a near balance between the reduction in TOA outgoing longwave radiation (OLR) and an increase in shortwave reflection, resulting in a net radiative effect near zero at the TOA (Hartmann et al. 2001). Despite this near-zero net effect on the TOA, radiative balance convective systems have a strong effect on the redistribution of the vertical profile of radiative heating in the atmosphere (Churchill 1992, Wong et al. 1993, Jensen et al. 2002, Jensen and Del Genio 2003). Using improved versions of algorithms developed in past work by Dr. Jensen (Jensen et al. 2002, Jensen and Del Genio 2003) the MJO field campaign data set will be used to further define typical radiative heating profiles within deep convective clouds and how they compare to the latent heating profile. The previous results (Jensen and Del Genio 2003) showed that net radiative heating could account for as much as $20 \%$ of the total diabatic heating in some of these systems.

Factors limiting convective cloud-top height

Johnson et al. (1999) used radar data from the TOGA-COARE to identify a trimodal distribution in tropical convective clouds that included shallow trade wind cumulus, cumulus congestus and deep convective clouds. Cumulus congestus clouds, with moderate shortwave albedos and cloud-top temperatures near freezing, occur fairly often in the tropics. These clouds may play an important role in the evolution of the MJO and the regulation of relative humidity in the mid-troposphere. Despite this importance, they are not necessarily simulated very well in global climate models. Of particular importance is the environmental factors that limit the depth of convective clouds. Previous work by Dr. Jensen (Jensen and Del Genio 2006) using observations from the ARM Nauru facility suggested that mid-level humidity played a significant role in defining the presence of cumulus congestus clouds versus deep convection. Other researchers have suggested that rather than a trimodal distribution of tropical convective clouds, there is a continuum in convective cloud top heights. The data collected during this field campaign, especially the increased radiosondes and the areal sampling from the scanning radar, could help address both the distribution of convective cloud types and the reasons for this distribution.

\section{Precipitation Regime Identification Artificial Neural Network}

Ed Luke and Andrew Vogelmann (BNL) have been developing an artificial neural network-based technique that uses texture information from geostationary satellite IR observations to identify different precipitation regimes in convective clouds (i.e., deep convection, precipitating anvil, non-precipitating anvil, mid-level convection, and shallow convection). The networks were trained using C-POL data from Darwin, and preliminary results for the TWP-ICE Period suggest a capability for identifying these precipitation regimes. This work was presented at the last ARM Science Team Meeting TWP-ICE breakout session. Data sets from different tropical regions (which have different types of convection) are needed to enhance and test the technique, which would enable extending its applicability across the broader TWP region. The Manus observations would be used to accomplish this for an important geographical regime - the maritime Tropical Warm Pool - that is particularly important and distinctively different from regions where C-POL data are currently available (Darwin and Kwajalein). Further, the developments enabled by the Manus data potentially provide the means of using the IR data to "extrapolate" the Manus observations beyond the radius observed by the C-POL radar. 


\section{Comparisons with satellites and models}

The data also lend themselves to various comparison activities for both satellite retrievals and model output, as was done with the data set from the TWP-ICE experiment (Wang and Liu 2009, Wang et al. 2009). In particular, Dr. Leung will investigate tropical convection and scale interactions with WRF model simulations. Through the INCITE Climate Science Computational End Station project, we will run cloud-resolving simulations over the Maritime Continents at 1-, 2-, and 4-km resolution, together with some aqua-planet-type tropical channel simulations to investigate tropical convection and scale interactions. Through a collaborative ARM project with NCAR (Jimy Dudhia, Bill Kuo, and Andy Heymsfield), we will produce high-resolution analysis of the atmosphere using WRF and data assimilation over the tropics to improve the water vapor distribution in the model. In addition, many simulations will be performed driven by the analysis to study clouds and improving cloud parameterizations. Scientists at PNNL will use the AMIE data sets to evaluate microphysical, ice nucleation, and planetary boundary layer parameterizations in both the WRF and CAM4 models.

In terms of satellite retrieval analysis, Drs. Ackerman and Marchand of the University of Washington are conducting CloudSat comparisons with the TWP site data. The C-POL and scanning radar data sets will be useful for placing the MMCR data in context and understanding differences between CloudSat and MMCR statistics. Dr. Minnis will be performing comparisons with cloud retrievals from MTSAT, MODIS, VIRS on TRMM, and CALIPSO. He will also perform comparisons of TOA radiative fluxes measured by CERES on Aqua and Terra and estimated from narrowband measurements taken by MTSAT.

\subsection{Data Processing and Expected Final Products}

Drs. Schumacher and May will be responsible for helping to process and interpret the C-POL data into scientifically useful form, similar to the data products from TWP-ICE and the BoM data products for the Gunn Point C-POL.

The TWP Site Scientist Team (Drs. Long, McFarlane, and Wang) will be responsible for monitoring and quality assessment of the ancillary site data. In addition, several useful products will be produced, including:

- Radiative Flux Analysis processing of the ancillary and ARM Manus site data.

- Vertical profiles of cloud microphysical properties and radiative heating rate profiles, similar to those submitted in the past for the TWP sites as a PI Product by Dr. McFarlane and Dr. J Mather, will be produced for the field campaign period.

The above data sets are part of the TWP-ICE model intercomparison data set (Fridlind et al. 2008) and will likely be used as part of a similar data set for model intercomparison for the AMIE experiment.

- A fine-resolution model run of the WRF model will be used to produce output for the field campaign period.

Dr. Minnis will be responsible for timely production of the relevant satellite data. In addition to the standard cloud retrievals and surface and TOA radiative flux estimates from the Japanese MTSAT 
satellite data covering the region (http://www-angler.larc.nasa.gov/cgibin/satimage/cloudProducts1.cgi?domain=mtmanus), his group will provide high-resolution $(1.25 \mathrm{~km})$ retrievals for a $1^{\circ}$ area centered at the site, $1-\mathrm{km}$ retrievals from MODIS on Aqua and Terra, and 2-km retrievals from VIRS on TRMM. He will provide broadband flux retrievals from CERES on Terra and Aqua for the same domain. Assuming the appropriate satellites are still operating, he will also provide a data set consisting of CALIPSO-CloudSat and GLAS profiles matched with radiances and retrievals from Aqua MODIS (Minnis et al. 2007) as well as MTSAT.

Dr. Xie will be responsible for production of the Variational Analysis modeling product for the field campaign period.

\subsection{Project Management}

The members of the project steering committee have a wide range of expertise in climate and radiative transfer modeling, data analysis, TWP science issues, and participation in field experiments that will enable successful execution of the project. The field campaign steering committee includes members of the steering committees of the Aerosol Life Cycle; Cloud Life Cycle; and Cloud, Aerosol, and Precipitation Interactions working groups, indicating the broad utility of the proposed field campaign to Atmospheric System Research. The broad membership in the committee will also ensure that the data sets collected will be appropriate for both process understanding and model evaluation. Some of the specific roles of the science team personnel include the following:

- Dr. Long will lead the project, interface with TWP Operations and other ARM personnel as needed, coordinate field campaign activities, and be responsible for overall management of the field campaign.

- Drs. Schumacher and May will assume primary responsibility for the C-band radar data that is produced by the experiment. Dr. May will also be responsible for use of BoM products in prediction of the MJO phase for the field campaign.

- The TWP Site Scientist Team will share responsibility for monitoring the performance and data from the ancillary site and perform overall coordination between the various efforts/groups associated with all the aspects of the field campaign.

- Dr. Minnis will be responsible for issues related to collection and delivery of the relevant satellite data.

- Drs. Klein and Del Genio will assume responsibility for oversight of modeling aspects associated with the field campaign, including interactions with the relevant ASR working groups with respect to modeling activities and efforts.

- Dr. Jakob will take responsibility for coordinating the inclusion of the 8-per-day sonde launch data into the ECMWF reanalysis products.

- All members of the steering committee will contribute expertise to discussions regarding the scientific aspects of the field campaign and promote use of the field campaign data in appropriate and related research. 


\subsection{ARM Critical Instruments and VAPs}

The success of the Manus MJO field campaign depends on collecting scientific quality data, including the measurements routinely collected at the ARM Manus site. However, there are certain ARM measurements that are especially critical to the detailed investigations of the MJO phenomenon. Thus, these measurements likely require extra effort to ensure performance for the duration of the field campaign period, such as inspection, testing, and maintenance performed before the start of the field campaign and close monitoring by Instrument Mentors during the field campaign. The list of critical measurements is as follows:

- Sondes (including adequate backup balloon gas and spare Digicora)

- C-band scanning precipitation radar

- Scanning cloud radar

- Surface flux (ECOR) over nearby forested area with upwelling (GndRad) radiation measurements moved to the flux tower

- ARSCL suite (MMCR, MPL,VCeil)

- MWR

- surface radiation (SkyRad) and met (SMET)

- MFRSR

Similar to the critical measurements listed above, some ARM value-added products (VAPs) are also especially critical for the success of the ultimate scientific use of field experiment data. The list of critical VAPs is as follows:

- ARSCL

- MWR Retrievals

- Merged Sounding

- Surface flux product

- QCRad

- MFRSR suite (Langley, AOD, COD)

- Variational Analysis Model Forcing

\subsection{References}

Benedict, JJ, and DA Randall. 2007. "Observed characteristics of the MJO relative to maximum rainfall.” Journal of Atmospheric Science 64: 2332-2354.

Bladé, I, and DL Hartmann. 1993. "Tropical intraseasonal oscillations in a simple nonlinear model." Journal of Atmospheric Science 50: 2922-2939. 
Chen, Y, and AD Del Genio. 2009. "Evaluation of tropical cloud regimes in observations and a general circulation model." Climate Dynamics 32: 355-369.

Churchill, DD. 1992. "Vertical retrieval of solar and infrared irradiances in the stratiform regions of EMEX cloud clusters." Journal of Applied Meteorology 31: 1229-1247.

Derbyshire, SH, I Beau, P Bechtold, J-Y Grandpeix, J-M Piriou, J-L Redelsperger, and PMM Soares. 2004. "Sensitivity of moist convection to environmental humidity." Quarterly Journal of the Royal Meteorological Society 130: 3055-3079.

Fridlind, A, and co-authors. 2008. "Joint ARM/GCSS/SPARC TWP-ICE CRM intercomparison study: description, preliminary results, and invitation to participate." Poster presented at the AGU Fall Meeting, Dec 15-19, San Francisco, California.

Hartmann, DL, LA Moy and Q Fu. 2001. "Tropical convection and the energy balance at the top of the atmosphere." Journal of Climate 14: 4495-4511.

$\mathrm{Hu}, \mathrm{Q}$, and DA Randall. 1994. "Low-frequency oscillations in radiative-convective systems." Journal of Atmospheric Science 51: 1089-1099.

Hume, T, and C Jakob. 2007. "Ensemble Single Column Model (ESCM) validation in the Tropical Western Pacific." Journal of Geophysical Research 112: D10206, doi:10:1029/2006JD008018.

Inness, PM, and JM Slingo. 2003. "Simulation of the Madden-Julian oscillation in a coupled general circulation model. Part I: Comparison with observations and an atmosphere-only GCM." Journal of Climate 16: 345-364.

Inness, PM, JM Slingo, E Guilyardi, and J Cole. 2003. "Simulation of the Madden-Julian Oscillation in a coupled General Circulation model. Part II: The role of the basic state." Journal of Climate 16(3): $365-382$.

Jakob, C, T Hume, K Cheung, and L Davies. 2008. "Ensemble single column modeling - a new approach to an old problem." Presented at the ARM Cloud Modeling WG Meeting.

Jensen, MP, TP Ackerman, and SM Sekelsky. 2002. "Radiative impacts of anvil outflow during the Maritime Continent Thunderstorm Experiment." Journal of Applied Meteorology 41: 473-487.

Jensen, MP, and AD Del Genio. 2003. "Radiative and microphysical characteristics of deep convective systems in the Tropical Western Pacific." Journal of Applied Meteorology 42: 1234-1254.

Jensen, MP and AD Del Genio. 2006. "Factors limiting convective cloud top height at the ARM Nauru Island climate research facility." Journal of Climate 19: 2105-2117.

Johnson, RH, TM Rickenbach, SA Rutledge, PE Cieseliski, and WH Shubert. 1999. "Trimodal characteristics of tropical convection." Journal of Climate 12: 2397-2418.

Kemball-Cook, SR, and BC Weare. 2001. "The onset of convection in the Madden-Julian oscillation." Journal of Climate 14: 780-793. 
Lin, J-L, GN Kiladis, BE Mapes, KM Weickmann, KR Sperber, WY Lin, M Wheeler, SD Schubert, A Del Genio, LJ Donner, S Emori, J-F Gueremy, F Hourdin, PJ Rasch, E Roeckner, and JF Scinocca. 2006. "Tropical intraseasonal variability in 14 IPCC AR4 climate models. Part I: Convective signals." Journal of Climate 19: 2665-2690.

Lin, J-L, B Mapes, M Zhang, and M Newman. 2004. "Stratiform precipitation, vertical heating profiles and the Madden-Julian oscillation.” Journal of Atmospheric Science 61: 296-309.

Madden, RA, and PR Julian. 1994. "Observations of the 40-50 day tropical oscillation - A review." Monthly Weather Review 122: 814-837.

Mapes, BE. 2000. "Convective inhibition, subgrid-scale triggering energy, and stratiform instability in a toy tropical wave model." Journal of Atmospheric Science 57: 1515-1535.

Mather, JH, SA McFarlane, MA Miller, and KL Johnson. 2007. "Cloud properties and associated heating rates in the tropical western Pacific." Journal of Geophysical Research 112: D05201.

McFarlane, SA, CN Long, and DM Flynn. 2005. "Impact of island-induced clouds on surface measurements: Analysis of the ARM Nauru Island Effect Study data." Journal of Applied Meteorology 44: $1045-1065$.

Sobel, AH, ED Maloney, G Bellon, and DE Frierson. 2008. "The role of surface heat fluxes in tropical intraseasonal oscillations." Nature Geoscience 1: 653-657.

Ushiyama, T, S Satoh, and K Takeuchi. 1995. "Time and space variations of mesoscale rainfalls and their relation to the large-scale field in the western tropical Pacific." Journal of the Meteorological Society of Japan 73: 379-392.

Waliser, DE, C Jones, J-KE Schemm, and NE Graham. 1999. "A statistical extended-range tropical forecast model based on the slow evolution of the Madden-Julian oscillation." Journal of Climate 12: $1918-1939$.

Wang Y, CN Long, JH Mather, and XD Liu. 2010. "Convective signals from surface measurements at ARM Tropical Western Pacific site: Manus.” Climate Dynamics, doi:10.1007/s00382-009-0736-z.

Wang W, and X Liu. 2009. "Evaluating deep updraft formulation in NCAR CAM3 with high-resolution WRF simulations during ARM TWP-ICE.” Geophysical Research Letters 36: L04701, doi:10.1029/2008GL036692.

Wang W, X Liu, S Xie, J Boyle, and SA McFarlane. 2009. "Testing a new ice microphysics parameterization in NCAR CAM3 using TWP-ICE Data." Journal of Geophysical ResearchAtmospheres, in revision.

Wheeler, M, and H Hendon. 2004. "An all-season real-time multivariate MJO index: development of an index for monitoring and prediction." Monthly Weather Review 132, 1917-1932.

Wheeler, M, and KM Weickmann. 2001. "Real-time monitoring and prediction of modes of coherent synoptic to intraseasonal tropical variability." Monthly Weather Review 129: 2677-2694. 
Wong, T, GL Stephens, PW Stackhouse and FPJ Valero. 1993. "The radiative budgets of a tropical mesoscale convective system during the EMEX-STEP-AMEX experiment. 2. Model results." Journal of Geophysical Research 98: 8695-8711.

Wu, X, L Deng, X Song, G Vettoretti, WR Peltier, and GJ Zhang. 2007. "Impact of a modified convective scheme on the MJO and ENSO in a coupled climate model." Geophysical Research Letters 34: L16823, doi:10.1029/2007GL030637.

Xie, S, R Cederwall, and M Zhang. 2004. "Developing long-term single-column model/cloud systemresolving model forcing using numerical weather prediction products constrained by surface and top of the atmosphere observations." Journal of Geophysical Research 109: D01104, doi:10.1029/2003JD004045.

Xie, S, T Hume, C Jakob, S Klein, R McCoy, and M Zhang. 2009. " 'Observed large-scale conditions and diabatic heating and drying profiles during TWP-ICE." Journal of Climate, in revision.

Zhang, C. 2005. "Madden-Julian Oscillation." Reviews of Geophysics 43: RG2003, doi:10.1029/2004RG000158.

Zhang, C, M Dong, S Gualdi HH Hendon, ED Maloney, A Marchall, KR Sperber, and W Wang. 2006. "Simulations of the Madden-Julian Oscillation in four pairs of coupled and uncoupled global models." Climate Dynamics 27: 573-592, doi:10.1007/s00382-006-0148-2.

Zhang, MH and JL Lin. 1997. "Constrained variational analysis of sounding data based on columnintegrated budgets of mass, heat, moisture, and momentum: approach and application to ARM measurements. Journal of Atmospheric Science 54: doi:10.1175/15200469(1997)054<1503:CVAOSD>2.0.CO;2.

Zhang, MH, JL Lin, RT Cederwall, JJ Yio, and SC Xie. 2001. "Objective analysis of ARM IOP data: method and sensitivity. Monthly Weather Review 129: doi:10.1175/1520-

0493(2001)129<0295:OAOAID>2.0.CO;2. 


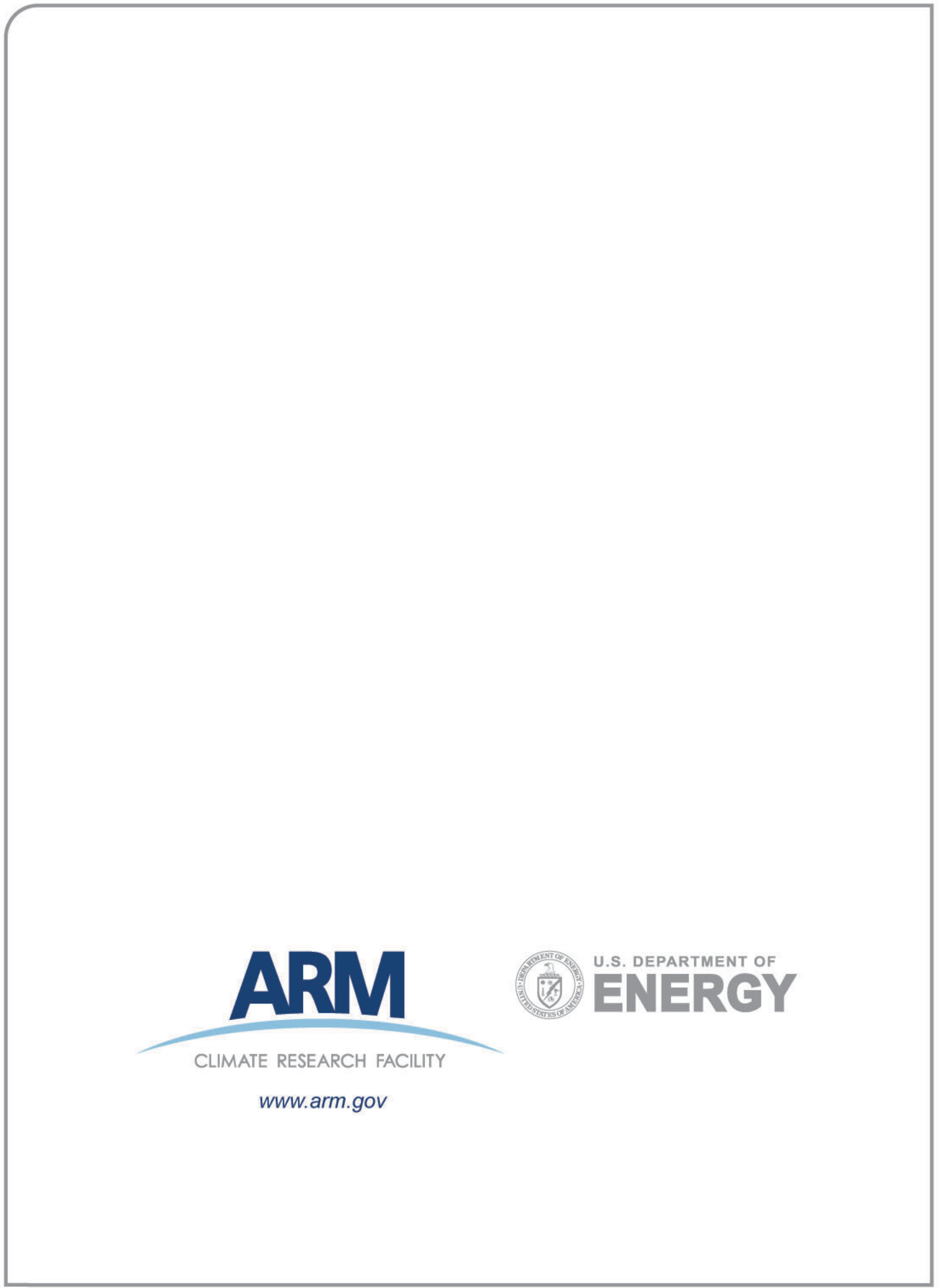

